\title{
CONTENTS
}

\section{BEPS Articles}

122 BEPS Action 6: Tax Treaty Abuse

Luc De Broe E Joris Luts

147 The Agency Permanent Establishment in BEPS Action 7: Treaty Abuse or Business Abuse?

Arthur Pleijsier

\section{Articles}

154 Blueprint for Reform of VAT Rates in Europe

Rita de La Feria

172 Some Fiscal Issues of the Charter of Fundamental Rights of the European Union

E. Poelmann

178 The 2014 Update to the OECD Commentary: A Targeted Hybrid Approach to Beneficial Ownership

Adrian Wardzynski

$191 \quad$ Location Savings: International and Indian Perspective

Pankaj Jain E Vikram Chand

198 Andorra: Exchange of Information and New Tax System in the Context of the OECD's and EU's Initiatives

Alberto Vega

\section{Conference Report}

208

Music and Taxation

Dick Molenaar E Mario Tenore 


\title{
ARTICLE
}

\section{Location Savings: International and Indian Perspective}

\author{
Pankaj Jain \&Vikram Chand*
}

\begin{abstract}
Outsourcing of operations from high cost countries to low cost countries has given birth to the location savings concept. Overtime, a related broader concept of location specific advantages (LSA) bas emerged, the exploitation of which gives rise to location rents. The determination and allocation of location savings/LSA and rents is a key TP issue - especially in developing countries. This article outlines the approach expressed on the aforementioned issue, in the US TP regulations (and court practise), OECD TP Guidelines and the UN TP Manual. Thereafter, the approach of the Indian tax administration and Courts is scrutinized in light of the international guidance. Finally, the authors provide their view on the road ahead for determination and allocation of location savings.
\end{abstract}

\section{BACKGROUND}

Globalization and competition has led Multinational Enterprises (MNEs) to move or establish operations in low cost jurisdictions and take advantage of the resultant savings. MNEs consider developing economies (such as BRICS $^{1}$ ) as lucrative locations for outsourcing routine manufacturing and services activities, predominantly because of the availability of low cost skilled workforce and low production costs. These growing economies also provide opportunities to MNEs in terms of differentiated value-addition, innovation, market penetration, and so on, even though the initial value proposition to move to such locations hinged mainly on cost savings. Outsourcing to low cost jurisdictions is no longer an option for MNEs, but an essential ingredient to remain competitive on the world stage.

The setting up of manufacturing and services facilities in low cost countries and the resultant cost savings has given rise to the concept of location savings. ${ }^{2}$ In a nutshell, location savings are the cost savings (net of dis-savings) realized by a MNE as a result of relocating certain activities to a low cost jurisdiction. ${ }^{3}$ The possibility to derive location savings may vary from one jurisdiction to another, depending on various factors such as lower labour, raw material, transportation, rental, training and infrastructure costs, or higher subsidies and tax incentives. ${ }^{4}$ Overtime, a related broader concept of location specific advantages (LSA) has emerged, which recognizes the existence and importance of other location specific factors of the relevant geographic market, both on supply and demand side, that may provide some advantages to the MNE, in addition to costs savings on relocation. The exploitation of such LSAs gives rise to location rents. ${ }^{5}$

From a Transfer Pricing (TP) perspective, the debate has arisen as to, if location savings/LSAs arise, which jurisdiction in relocation circumstances should tax them. While the trend towards relocation of operations to low cost countries has existed for long, the debate has taken centre stage due the fact that tax authorities in developing countries (like India) argue that the economic benefit arising to the MNE due to shifting of operations to a low cost jurisdiction should accrue to the country where the operations are carried out. ${ }^{6}$ The aggressive approach of the tax authorities in the application of location savings for

\section{Notes}

Pankaj Jain is the Associate Director, International Tax \& Transfer Pricing, Ernst \& Young, Hyderabad, India. The author can be contacted on PankajJain@in.ey.com ·Vikram Chand, is the Academic Coordinator, Masters of Advanced Studies in International Taxation, University of Lausanne, Switzerland. The author can be contacted on vikram.chand@unil.ch.

The BRICS are Brazil, Russia, India, China, and South Africa respectively.

Steven N. Allen et al. 'Location Savings - A US Perspective', International Transfer Pricing Journal, IBFD, July/August (2004), p. 158.

Sebastien Gonnet, Pim Fris and Tommaso Coriano, 'Location specific advantages - principles', Transfer Pricing International Journal, BNA (2011), available on http:// www.nera.com/nera-files/PUB_TPI_Journal_0611.pdf, p. 1.

Pinakin Desai and Shefali Goradia, 'General Report, Cross-border outsourcing - issues, strategies and solutions', IFA Cahiers de Droit Fiscal International (2014), Vol. 99a, p. 49.

Gonnet, Fris, Coriano, supra n. 3, p. 3.

Desai and Goradia, supra n. 4, p. 50 
determining the pricing for intra-group transactions is a grave concern for MNEs. Accordingly, a key emerging TP issue is the determination of location savings/LSAs/ location rents and its allocation between group companies.

This article outlines the approach, expressed for the aforementioned issue, in the US TP regulations ${ }^{7}$ (and court practise), OECD TP Guidelines ${ }^{8}$ and UN TP Manual $^{9}$ (section 2). Thereafter, the approach of the Indian tax administration and Courts is discussed in light of the international guidance (section 3). Then, the authors provide their view on the road ahead for the determination and allocation of location savings (section 4).

\section{The US, OECD AND UN APproach}

\section{I The US Approach}

The US regulations neither define nor provide a mechanism to determine location savings. In a limited manner, it is stated that the allocation of location savings depends on the relative competitive positions of buyers and sellers in each market. ${ }^{10}$ The regulations, through an example of an US apparel design corporation, which contracts to its subsidiary in a low cost country, manufacturing of clothes (which does not require significant specialized knowledge and could be performed by several competitors in geographic markets similar to the subsidiaries' location), explain that under arm's length conditions, additional profit on account of location savings would not be retained by the subsidiary, because of the competitive positions of the parties. ${ }^{11}$
The US Tax Court, on several occasions, has commented directly/indirectly on the allocation of location savings among associated enterprises (AE). Notably, in the Sunstrand ${ }^{12}$ and Compaq ${ }^{13}$ cases, wherein a US parent established a subsidiary in Singapore to optimize on manufacturing costs, the US Tax Court ruled that location savings should be allocated to the offshore jurisdictions because, in the former case the subsidiary, which was characterized as a full fledged manufacturer, has a monopolistic position for manufacturing of aviation spare parts, ${ }^{14}$ and in the latter case, the subsidiary was the only manufacturer of computer components in its territory that could provide the necessary quality standards and production flexibility that the US parent needed. ${ }^{15}$ While the analysis applied by the Tax Court varies in these two cases, the Court seems to have visualized what independent parties would have done on an arm's length basis taking into consideration the ownership/uniqueness of intangibles and the bargaining power of the parties to decide that the location savings should be retained by the low cost jurisdiction. ${ }^{16}$

\subsection{The OECD Approach}

The OECD TP Guidelines ${ }^{17}$ define ${ }^{18}$ the concept of location savings ${ }^{19}$ in the context of business restructurings. The guidelines do not comment on how location savings should be determined but state the location savings may be shared between related parties on the basis of what independent parties would have agreed in similar circumstances, in particular, taking into

\section{Notes}

All references in this article are to the US Treasury Regulations (1994 as update from time to time) issued under s. 482, US Internal Revenue Code (1986), unless otherwise stated.

All references in this article are to the OECD Transfer Pricing Guidelines for Multinational Enterprises and Tax Administrations (22 Jul. 2010) unless otherwise stated.

All references in this article are to the United Nations Practical Manual on Transfer Pricing for developing countries (2013) unless otherwise stated.

Section 1.482-1(d)(4)(ii)(C), US Treasury Regulations (1994); Allen et al. supra n. 2, p. 159

Section 1.482-1(d)(4)(ii)(D), US Treasury Regulations (1994).

US Tax Court: Sundstrand Corporation and Subsidiaries v. Commissioner of Internal Revenue, 96 TC 226, 19 Feb. 1991.

US Tax Court: Compaq Computer Corporation and Subsidiaries v. Commissioner of Internal Revenue, TC Memo 1999-220, 2 Jul. 1999.

Allen et al. supra n. 2, pp 160-161; Brian P Arthur, Ashleigh E Herbert, Marc M Levey, 'US Report, Cross-border outsourcing - issues, strategies and solutions', IFA Cahiers de Droit Fiscal International (2014), Vol. 99a, pp 798-799.

15 Allen et al. supra n. 2, pp 161-162; Arthur, Herbert, Levey, supra n. 14; Also see Martijn A de Lange and Paul WH Lankhorst, 'The Impact of Location Advantages on the Transfer Pricing of Multinationals: On the Chinese Love for European Designer Handbags and Lower Production Costs in India', International Transfer Pricing Journal, IBFD, July/ August (2014), p. 227

16 Allen et al. supra n. 2, p. 162; It is pertinent to note that US Courts analysed the transfer price of the manufactured goods and the royalty payment for the use of intangibles seperately due to their independent significance. Further, even in the absence of local comparables in the offshore jurisdiction, comparable transactions in the US geography were considered on the finding that the market for the manufactured product is global in scope and competitive; Also, it should be noted that the US and India have repeatedly debated on the location savings issue in Mutual Agreement Procedures and many cases are pending before the competent authorities. Arthur, Herbert, Levey, supra n. 14 , p. 800.

17 The OECD's approach on location savings can be traced back to the OECD's discussion draft on TP aspects of Business Restructurings. See paras 188-193., OECD Discussion Draft for Public Comment on Transfer Pricing Aspects of Business Restructurings (19 September 2008). The approach was subsequently incorporated in paras 9.148-9.153, OECD TP Guidelines (2010). The view was thereafter elaborated in the OECD's paper on location savings prepared by the OECD Secretariat. See paras 1-11, OECD Paper on Location Savings (July 2010).

18 Gonnet, Fris, Coriano, supra n. 3, p. 2.

19 Paragraph 9.148, OECD TP Guidelines (2010). The concept is nevertheless defined in the OECD's paper on location savings 'as the net savings in costs that may be derived by an MNE group that relocates some of its activities to a place where labor or real estate expenditures, to cite only a couple of examples, are lower than in the location where the activities were initially performed'. OECD Paper, supra. n. 17, para. 2. Also see J. Scott Wilkie, 'Intangibles and Location Benefits', Bulletin for International Taxation, IBFD, May (2014 - Online Version), s. 4. 
consideration the functional (FAR) analysis of the parties and their respective bargaining powers. ${ }^{20}$

Two examples ${ }^{21}$ are provided to elaborate on the concept of bargaining power. The first example ${ }^{22}$ deals with relocating basic manufacturing operations (of clothes) from a Country A enterprise to a Country B enterprise under a contract manufacturing arrangement. Post restructuring, all intellectual property (including brand) is continued to be owned by the Country A enterprise which also bears substantial risks. It is stated that the relocated activity is highly competitive and hence it is possible to use several third party manufacturers. As the bargaining power of the contract manufacturer in Country B is relatively low, the guidelines state that this entity would be attributed, if any, very little part of the location savings, because in an arm's length scenario the third party manufacturers cannot demand higher compensation in a competitive market. ${ }^{23}$ The second example, deals with relocation of specialized engineering services from a Country $\mathrm{X}$ enterprise to a Country $\mathrm{Y}$ enterprise also to optimize labour costs. However, in contrast with the previous example, the Country $\mathrm{Y}$ enterprise is the only enterprise in its territory to provide the services because it meets the MNE's required quality standards. The guidelines state that location savings (till the extent the cost savings are not passed on to customers) could be attributed to Country $\mathrm{Y}$ by inter alia using the transactional profit split method (PSM) because the bargaining power of Country $\mathrm{Y}$ enterprise is higher. ${ }^{24}$

Further, in its project on revising Chapter VI on intangibles, ${ }^{25}$ the OECD systematically states that its analysis in Chapter IX-Business Restructuring applies in all cases where location savings is present and is not restricted to restructurings. ${ }^{26}$ The draft guidance states, in determining the location savings that are to be shared among related parties it is necessary to consider whether location savings exist; the amount of any location savings; the extent to which location savings are either retained by a member or members of the MNE group or are passed on to independent customers or suppliers; and where location savings are not fully passed on to independent customers or suppliers, the manner in which independent enterprises operating under similar circumstances would allocate any retained net location savings. ${ }^{27}$ It is stated that if reliable local comparables exist then those local market comparables will provide the most reliable indication regarding how location savings (not passed on to customers or suppliers) should be allocated amongst two or more AEs. Thus, when reliable local market comparables can be used to determine the arms length price, comparability adjustments for location savings should not be required (a preference for local comparables is expressed). ${ }^{28}$ Conversely, it is also provided that in the absence of reliable uncontrolled prices, specific comparability adjustments for location savings are required. ${ }^{29}$

\subsection{The UN Approach}

The UN TP Manual discusses location savings in the chapter on Comparability Analysis ${ }^{30}$ in a holistic manner. Location savings have been defined as the net cost savings $^{31}$ that an MNE realizes as a result of relocation of operations from a high cost jurisdiction to a low cost jurisdiction. ${ }^{32}$ It is also provided that relocation of a business also gives rise to geographical benefits in addition to location savings. These benefits could include availability of highly skilled workforce, proximity to growing local/regional markets, large client base with

\section{Notes}

Paragraph 9.149, OECD TP Guidelines (2010).

21 These examples have been discussed in the form of case studies by the general reporters in the IFA 2014 General Report on outsourcing. See Desai and Goradia, supra n. 4, pp 54-56.

22 The example is similar to the example provided in the US TP regulations. See supra, n. 11.

Paragraphs 9.150-9.151, OECD TP Guidelines (2010).

24 Paragraphs 9.152-9.153, OECD TP Guidelines (2010). In our view, it is debatable to whom the location savings should be attributed. It could certainly be argued that an allocation may take place to the Country Y enterprise as that enterprise performs a highly skilled service in a sector with limited competition. Thus, its bargaining power is high. On the contrary it may be argued that the bargaining power is not the sole parameter to allocate location savings. The Country X enterprise may still be classified as a full fledged service provider which undertakes substantial risks. Thus, location savings should be attributed to Country X. See Desai and Goradia, supra n. 4, pp 55-56.

25 OECD Revised Discussion Draft on Transfer Pricing Aspects of Intangibles (30 Jul. 2013). The project also forms a part of Action point 8 of the OECD BEPS Plan. See OECD Action Plan on Base Erosion and Profit Shifting (19 Jul. 2013).

26 OECD Intangibles, supra n. 25 , p. 5.

OECD Intangibles, supra n. 25, p. 5. The changes are proposed to be incorporated in Ch. I of the OECD TP Guidelines

Lange, Lankhorst, supra n. 15, p. 226

OECD Intangibles, supra n. 25 , p. 5 .

30 The Manual also includes an outline of country administrative practices of Brazil, China, India and South Africa. In this regard, China and India have provided their individual viewpoints inter alia on the concept of location savings and its consideration for determination of ALP.

31 Net cost savings is the difference between cost savings that arise from labour, raw material etc and dis-savings on account of factors such as poor quality of the power supply, higher costs for transportation, quality control, etc. para. 5.3.2.39, UN TP Manual (2013).

32 The UN Manual, in its description of location savings seems to refer only to a relocation of operations. This would be a deviation from the OECD's Intangibles Report, which states that location advantages are relevant not only in a business restructuring, but generally also in all situations where those are present. See Lange, Lankhorst, supra n. 15 , p. 227. 
increased spending capacity, superior information and distribution networks, advanced infrastructure and market premium. Such LSAs (that include location savings and geographical benefits) play a crucial role in increasing the profitability of the MNE and in determining the bargaining power of each of the associated enterprises. ${ }^{33}$ The incremental profit, if any derived from the exploitation of LSAs is defined as location rents. ${ }^{34}$ The Manual explains that the extent to which LSAs lead to location rents depends on the competitive factors relating to the end product and general access to LSAs. For example, it is stated that location rents might exist when a MNE has exclusive access to LSAs. ${ }^{35}$ However, location rents might not exist in a market where competitors also have access to LSAs, because most of the benefits of LSAs would be passed on to the customers through lower prices of products in a competitive market.

With respect to sharing of location rents, it is stated that the arms length attribution depends on competitive factors relating to access to the LSAs and realistic alternatives available to the associated enterprises given their respective bargaining power. ${ }^{36}$ Again, the bargaining power is viewed as a key metric that reflects the behaviour of two independent parties negotiating over their respective shares of savings/rents and can be used to determine the arm's length allocations when comparable uncontrolled transactions or benchmarks are not available. ${ }^{37}$

\section{INDIAN APPROACH}

\section{I Preliminary Remarks}

Over the last few years, the Indian tax administration has sought to allocate high mark-ups to captive Indian service centres by characterizing the Indian affiliate as 'high value' or 'high end' service providers that generates significant location savings to the MNE group. ${ }^{38}$ The administration has also been challenging cost plus remuneration models and in certain instances (particularly for research and development, software and procurement entities) have used the PSM for determining the arm's length profit allocation to India. ${ }^{39}$ The administration has provided its view on location savings in the UN TP Manual. The administration views that India provides MNEs many LSAs and the resultant location rents should be split appropriately between the parties. ${ }^{40}$ The view of the administration that a comparability analysis by benchmarking with local comparables will not take into account the benefit of location savings ${ }^{41}$ contradicts the view of the OECD and UN. The administration views that the arm's length compensation for location savings and rent should be such that both the parties would benefit from participating in the transaction. In other words, it should not be less than zero and yet not greater than the value of the locations rent. ${ }^{42}$ However, the approach of the administration has not been accepted by the Indian Courts as evidenced in the following two cases.

\subsection{The Li and Fung Case ${ }^{43}$}

In the Li \& Fung case, a Hong Kong entity (HK AE) provided product sourcing services to global customers. Based on the HK AE's advice, the customers entered into contracts directly with the third party vendors. The HK $\mathrm{AE}$ received remuneration from uncontrolled customers at $5 \%$ of the 'FOB value' 44 of products sourced. For the Indian market, the $\mathrm{HK}$ AE obtained sourcing services from its Indian related party (taxpayer). The taxpayer was remunerated on an operating cost plus $5 \%$ basis. The administration asserted that the taxpayer has performed all the critical functions, assumed significant risks and has used both tangibles and unique intangibles developed by it over a period of time such as supply chain management and human capital, which had provided significant advantages to the HK AE. Therefore, an additional profit on account of location savings should be attributed to the taxpayer. ${ }^{45}$ The taxpayer contented that neither the AE

\section{Notes}

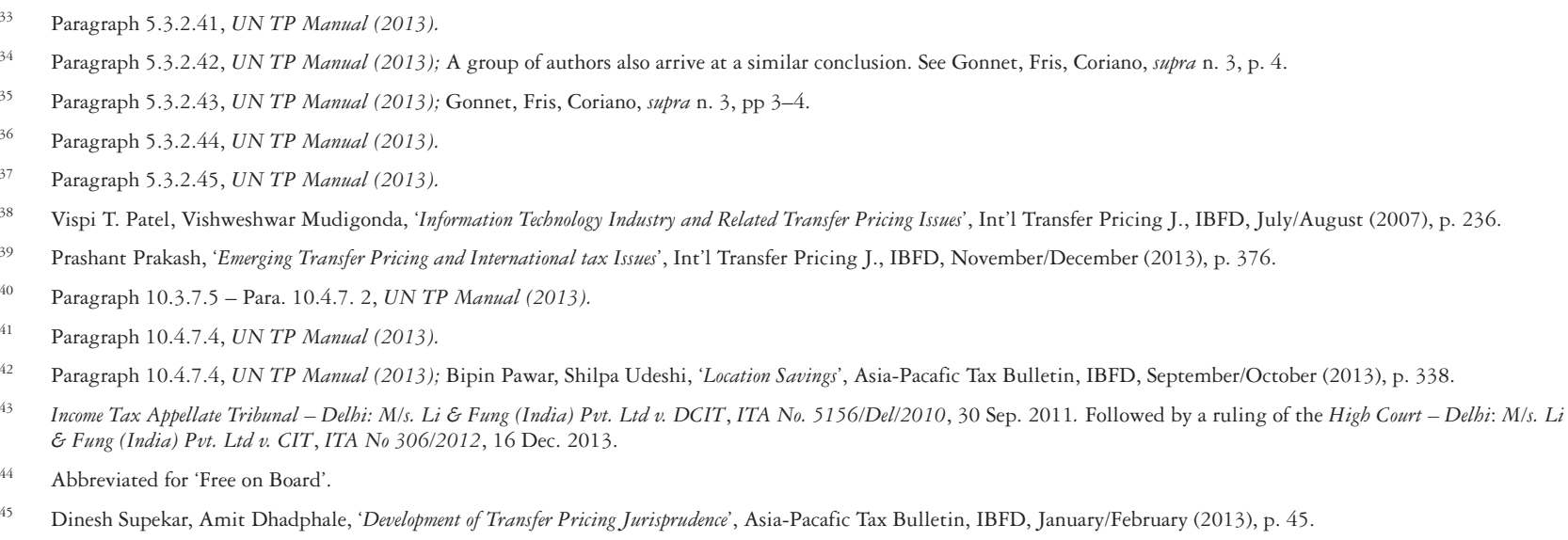


nor the taxpayer was a party to the transaction of export, as the finished goods were exported by third party vendors to customers directly and the taxpayer along with its $\mathrm{HK} \mathrm{AE}$ merely undertakes the sourcing services. Accordingly, location savings should only be attributed to the end purchaser and the taxpayer did not gain any advantage on account of location savings.

The Tribunal rejected the claim of the taxpayer that location savings was attributable to end customers and concluded that the HK AE has also been able to retain business because the taxpayer had a location advantage to procure low cost goods. The Tribunal ruled that location advantage needs to be considered and accordingly $80 \%$ of the $5 \%$ commission on FOB value of the goods sourced by the $\mathrm{AE}$, should be allocated to the taxpayer in India. 46 While the decision raises the question on relevance of location savings/LSAs in transfer pricing, it does not lay down an analytical framework to evaluate their existence, quantification, and attribution under arm's length conditions. On further appeal, the High Court, in the view of the authors, has rightfully overruled the ruling of the Tribunal. The HC ruled that the tax authorities have not brought any material on record to establish how, and to what extent the MNE enjoys location savings, and the Indian taxpayer bears significant risks. ${ }^{47}$ The High Court upheld the taxpayers pricing of cost plus mark-up of $5 \%$ as representing an arm's length remuneration for the functions performed, assets utilized, and risks assumed by it, based on the profit margins of comparable Indian companies selected by the taxpayer in its TP documentation. The High Court concluded that if any adjustments are warranted, they should be supported by demonstrable reason, based on objective facts and the relative evaluation of their weight and significance.

\subsection{The Gap International Souring Case ${ }^{48}$}

The taxpayer, an Indian company was engaged in providing procurement services to the GAP Group by facilitating sourcing of apparel merchandise from India and was remunerated on a cost plus $15 \%$ basis. The administration asserted that under arm's length conditions the taxpayer should be earning a commission of $5 \%$ on the FOB value of the goods sourced by the foreign enterprise through Indian vendors and accordingly made an upward adjustment. The tax authorities argued that the taxpayer was not a limited risk support service provider due to the fact that it played a critical role in the AE's value chain, undertook 'high value' procurement functions and created 'procurement intangibles' through its operations. Thus, the 'location savings' arising from sourcing in India should be factored in the remuneration model. The taxpayer argued that it was a low risk service provider that did not own any supply chain or human capital related intangibles. The Tribunal ruled that location savings arise to an industry as a whole. The intent of sourcing from low cost countries is to survive in stiff competition by providing lower prices to end customers. Hence, generally the advantage of location savings is passed on to the end customers via a competitive sales strategy. Further, it was held that the arm's length principle requires benchmarking to be done in the jurisdiction in which the taxpayer operates and therefore, comparables selected from that jurisdiction would also be entitled to the same location savings, which would generally be factored into their prices. This conclusion contrasts the view of the administration expressed in the UN TP Manual and resembles the OECD and UN view on the subject. ${ }^{49}$

\section{Determination and allocation of LOCATIONS SAVINGS: THE ROAD AHEAD}

While the framework for determining location savings/ LSAs/ rents in the UN TP Manual is laudable, the quantification of such parameters could be a highly complex exercise. To quantify location savings simply by computing the cost difference before and after relocations can be misleading. Detailed comparison of each element related to location savings is required. ${ }^{50}$ The Supreme Administrative Court of Finland in its recent ruling on relocation of manufacturing operations by a parent in Finland to its subsidiary in Estonia arrived at the conclusion that location savings could not be determined due to significant dissimilarities in the handicraft intensive manufacturing originally carried out in Finland as compared to the factory type manufacturing in Estonia (which had a significant impact on the cost base as well as the effectiveness of the manufacturing operations). The ruling indicates that location savings can be determined if the activity carried out in the high cost jurisdiction (pre location) and low cost jurisdiction (post location) is substantially similar. Nevertheless, the Court held that LSAs (such as low cost of production and access to better production technology) arose in Estonia and such LSAs

\section{Notes}

46 The tribunal seems to have reached this conclusion because it had agreed with the tax authorities view that the taxpayer had developed many unique intangibles and also human capital intangibles, which gave it a location advantage to procure low cost goods.

47 The High Court seems to have agreed that the taxpayer may have created human capital and supply chain intangibles. But these intangibles do not reveal how the taxpayers bear additional risks.

48 Income Tax Appellate Tribunal - Delbi: GAP International Sourcing v. ACIT, ITA Nos. 5147/Del2011 \& 228/Del/2012, 19 Sep. 2012.

49 See Pawar and Udeshi, supra n. 42, p. 338.

50 A reference can be made to Frisch matrix to identify if location rents exist. See Gonnet, Fris, Coriano, supra n. 3, p. 6. 
should be reflected in the arm's length compensation. ${ }^{51}$ Thus, even if location savings do not exist, LSAs (only geographical benefits) might exist. However, quantifying geographical benefits in an isolated manner is not a scientific task.

Even if location savings/LSAs and location rents are defined and quantified, it needs to be determined as to which entity should take the additional profits - the high cost jurisdiction entity or the low cost jurisdiction entity and in what proportion? The current guidance suggests the bargaining power analysis will serve as a useful starting point. Bargaining power is generally understood as the relative ability of parties in a situation to exert influence over each other. If both parties are on an equal footing in a debate, then they will have equal bargaining power, such as in a perfectly competitive market. However, (as indicated in the various examples discussed previously) the high cost country entity will have greater power, for example when its FAR analysis indicates that this entity plays an active role in the development, enhancement, maintenance, and protection of intangibles that are highly valuable for the MNE. In contrast, the bargaining power of the low cost country entity will be higher if, for example, it does not depend heavily on the intellectual property owner and adds value from its own side to the supply chain. To illustrate, in the aforementioned Finnish case, the Court analysed the bargaining power of the Estonian entity and stated that it was in a better position than its comparables because of its access to LSAs and competitive level in the market. Thus, a higher mark-up was justified. ${ }^{52}$ In the view of the authors, it could be a highly complex exercise to stimulate bargaining conditions among related parties. Conceptually, the authors doubt if genuine bargaining power among group member actually exits given the inherent nature of a MNE's business. ${ }^{53}$

The most direct way to apportion the location rents would be through utilizing the CUP ${ }^{54}$ or the TNMM $^{55}$ method using local market comparables. However, from a practical perspective, in most cases, local market comparables may not exist. Recently, the OECD released a discussion paper on TP Comparability Data and Developing Countries. ${ }^{56}$ The paper addresses concerns expressed by developing countries about the availability and quality of financial data needed for application of the arm's length principle. The following four approaches are suggested to address the concerns viz., (1) expanding access to data sources for comparables; ${ }^{57}$ (2) more effective use of data sources for comparables including the possibility of using foreign comparables or using the foreign affiliate as the tested party; ${ }^{58}$ (3) approaches to reducing reliance on direct comparables and resorting to other methods such as the PSM or value chain analysis or adopting safe harbours or use of publicly quoted commodity prices ${ }^{59}$ and; (4) using advance pricing agreements (APA) to prevent disputes and mutual agreement procedures to resolve disputes. ${ }^{60}$ The draft does provide some practical solutions on resolving TP issues with developing countries. Based on the second approach, it could be interesting to use foreign comparables for considering location savings in determining the arm's length price. In fact, the Chinese tax authorities, in the UN TP Manual, explain through an example of a contract research and development centre, its views on allocation of location savings by using foreign comparables, in the absence of local comparables. ${ }^{61}$ The approach seems pragmatic even though it defies arm's length logic as it does not take into consideration the bargaining power analysis Also, based on the third approach other complex methods may be considered such as the contribution analysis or the Shapely value (a game theory concept) ${ }^{62}$ under the PSM method to allocate location savings. While determination and allocation of location savings is a contentious issue, given the aggressive nature of tax administrations, it becomes imperative for taxpayers to maintain robust documentation by carefully considering and documenting all functions performed, assets used and risks assumed, as well as the bargaining power of all AEs

\section{Notes}

51 Merja Raunio, 'Supreme Administrative Court Ruling on Location Savings', Int'l Transfer Pricing J., IBFD, July/August (2013), pp 263-264; Also see Jari Ahonen and Ka Sajalahti, 'Finnish Report, Cross-border outsourcing - issues, strategies and solutions', IFA Cahiers de Droit Fiscal International (2014), pp 295-297.

Raunio, supra n. 51, pp 264-265.

Wilkie, supra n. 19, s. 4. Another concern is that a static determination of the bargaining power may not be appropriate as each parties power may change on a year to year basis.

Abbreviated for 'Comparable Uncontrolled Price Method'.

Abbreviated for 'Transactional Net Margin Method'.

OECD Paper on Transfer Pricing Comparability Data and Developing Countries (March 2014)

Ibid., paras $13-17$

Ibid., paras $18-23$.

Ibid., paras 24-28.

Ibid., paras 29-31.

See para. 10.3.3.9, UN TP Manual (2013).

Gonnet, Fris, Coriano, supra n. 3, pp 7-8. 
involved in the specific transaction(s). ${ }^{63}$ This would provide a solid foundation for supporting the consideration for location savings in intra-group pricing and defending during audits. Needless to say, if the taxpayer would like prevent double taxation and obtain upfront certainty, it may evaluate the issue of location savings, by resorting to the fourth approach i.e., entering into a bilateral or unilateral APA with the relevant jurisdiction. ${ }^{64}$

63 Lange, Lankhorst, supra n. 15, p. 230

64 News paper reports indicate that MNE's are asked to factor in location savings when they enter an APA with the Chinese tax authorities. 